\title{
Percepção sobre o desenvolvimento de competências profissionais no curso de ciências contábeis de acordo com o IAESB: uma análise com os egressos de 2011 a 2015
}

\author{
Perception about the development of professional competences in \\ accounting course in accordance with IAESB: an analysis with \\ graduates from 2011 to 2015
}

\author{
Paula Filócomo Barrese \\ Universidade Estadual de Londrina (UEL) \\ paulabarrese@hotmail.com
}

Graduanda em Ciências Contábeis na Universidade Estadual de Londrina (UEL)

Thayse Ruas Bastoni

Universidade Estadual de Londrina (UEL)

thaysebastoni@hotmail.com

Graduanda em Ciências Contábeis na Universidade Estadual de Londrina (UEL)

\author{
Daniel Ramos Nogueira \\ http://www.danielnogueira.com.br \\ Universidade Estadual de Londrina (UEL) \\ danielrnog@hotmail.com
}

Docente Adjunto da Universidade Estadual de Londrina (UEL), Doutor em Controladoria e Contabilidade (FEA-USP), Mestre em Contabilidade (UFPR).

\section{RESUMO}

Diante da necessidade constante de adaptação do profissional contábil à demanda do mercado de trabalho, os órgãos que regem a profissão buscam atualizar seus modelos a fim de garantir a competência de seus. Diante disso, este estudo tem como objetivo identificar a percepção do egresso do Curso de Ciências Contábeis em relação ao desenvolvimento dos resultados de aprendizagem, durante o período de graduação, que o IAESB estabelece como relevantes para atingir a competência profissional. Realizou-se uma pesquisa quantitativa com os egressos de 2011 a 2015. A partir dos resultados, há evidências de que as competências relacionadas aos Valores, Ética e Atitudes Profissionais foram as mais absorvidas. A pesquisa também verificou que estudantes graduados em 2011 e 2012 (PPP anterior) concordaram terem recebido mais informações sobre questões tributárias do que os recém formados.

Palavras-chave: Competência. Habilidades. Atitudes. IAESB. Contabilidade.

\section{ABSTRACT}

Faced with the constant need to adapt the accounting professional to the demand of the job market, the class concil that governing the profession seek to update their models to ensure the competence of its professionals. Thus, this study aims to identify the perception of graduates of Accounting Course for the development of learning outcomes that the IAESB 
BARRESE, P. F.; BASTONI, T. R.; NOGUEIRA, D. R. Percepção sobre o desenvolvimento de competências profissionais no curso de ciências contábeis de acordo com o IAESB: uma análise com os egressos de 2011 a 2015. Revista Unemat de Contabilidade, 2017. v. 6, n. 11.

establishes as relevant to achieve professional competence during the undergraduation period. For this, there was a quantitative study with the graduates of 2011 until 2015. From these results, there is evidence that the skills related to Values, Ethics and Professional Attitudes were more absorbed. The research also found that graduate students in 2011 and 2012 (previous pedagogical project) agreed they received more information about tax than new graduates.

Key-words: Competence. Skills. Attitudes. IAESB. Accounting.

\section{INTRODUÇÃO}

A contabilidade é uma das profissões que mais cresce no mundo. Segundo o relatório Nexus 1: The Accountancy Profession, Behind the Numbers, publicado pelo International Federation of Accountants (IFAC, 2015), em mais de 130 países nos quais possui representação, o emprego na área contábil cresceu acima da média em relação ao crescimento total de empregos no período de 2009 a 2013. No agrupamento de países intitulado como BRIC (Brasil, Rússia, Índia e China), esse crescimento ultrapassou 15\%, enquanto o crescimento em geral não superou $5 \%$.

Os órgãos que regem a profissão contábil, os quais são responsáveis por garantir a competência de seus profissionais no que diz respeito às expectativas do mercado, buscam adequar seus modelos a tais mudanças e, com isso, dão base às intituições de ensino para a atualização de seus currículos, com o propósito de formar profissionais aptos à atuação no mercado de trabalho (IAESB, 2015).

De acordo com o International Accounting Education Standards Board (IAESB, 2015, p. 7), “a competência profissional não se restringe ao conhecimento dos princípios, normas, conceitos, fatos e procedimentos, mas, sim, compreende a integração e aplicação da (a) Competência Técnica, (b) das Habilidades Profissionais e (c) dos Valores, Ética e Atitudes profissionais", os quais, respectivamente, estão descritos nos International Education Standards (IES) 2 (IAESB, 2014a), 3 (IAESB, 2014b) e 4 (IAESB, 2014c).

Com base no exposto, esta pesquisa busca esclarecer a seguinte questão: Qual a percepção do egresso do Curso de Ciências Contábeis em relação ao desenvolvimento, durante a graduação, dos resultados de aprendizagem que o IAESB estabelece como relevantes para atingir a competência profissional? Deste modo, o objetivo principal do estudo é identificar a percepção do egresso do Curso de Ciências Contábeis em relação ao desenvolvimento dos resultados de aprendizagem, durante a graduação, que o IAESB estabelece como relevantes para atingir a competência profissional. 
BARRESE, P. F.; BASTONI, T. R.; NOGUEIRA, D. R. Percepção sobre o desenvolvimento de competências profissionais no curso de ciências contábeis de acordo com o IAESB: uma análise com os egressos de 2011 a 2015. Revista Unemat de Contabilidade, 2017. v. 6, n. 11.

A escolha por abordar, estritamente, as competências introduzidas pelo IAESB é justificada pelo fato dos Padrões Internacionais de Educação terem sido reformulados recentemente (2014), alterando aspectos de sua estrutura. Além disso, espera-se contribuir com o desenvolvimento do processo de formação dos profissionais, para que possam aperfeiçoar as habilidades evidenciadas e, também, retificar os pontos que os egressos acreditam não terem desenvolvido durante o período de graduação.

A presente pesquisa está dividida em cinco partes, sendo que após esta introdução será descrito na literatura sobre o conceito de competência, a competência para a Contabilidade no Brasil e no mundo e ao final uma revisão sobre as pesquisas já existentes sobre o tema. $\mathrm{Na}$ sequência o tópico de aspectos metodológicos detalhará a classificação da pesquisa e o processo de coleta e análise dos dados. Em seguida há a apresentação e análise dos dados para ao final apresentam-se as considerações finais sobre a pesquisa com as conclusões, limitações e sugestões para futuras investigações.

\section{REVISÃO DE LITERATURA}

Em face de uma sociedade dinâmica, torna-se imprescindível que o profissional contábil atualize constantemente seu perfil, buscando atender às necessidades de seus clientes, os quais, segundo Leal, Soares e Sousa (2008), procuram por profissionais que possuam competências para entender o negócio, de forma que auxilie o gestor e participe de forma consciente nas decisões.

Neste contexto, observa-se que somente conhecimento técnico não é suficiente para obter sucesso no mercado de trabalho. O perfil do novo profissional contábil é mais completo, não restringindo-se apenas a competência técnica, mas sendo necessário também o domínio de habilidades profissionais e comportamento ético (IAESB, 2014a; IAESB, 2014b; IAESB, 2014c)

\subsection{O conceito de Competência}

Segundo Le Boterf (1995 apud FLEURY; FLEURY, 2004, p. 48), “competência é um saber agir responsável e que é reconhecido pelos outros. Implica saber como mobilizar, integrar e transferir os conhecimentos, recursos e habilidades, em um determinado contexto profissional".

Conforme Fleury e Fleury (2004, p. 45), o trabalho deixou de ser uma série de tarefas 
BARRESE, P. F.; BASTONI, T. R.; NOGUEIRA, D. R. Percepção sobre o desenvolvimento de competências profissionais no curso de ciências contábeis de acordo com o IAESB: uma análise com os egressos de 2011 a 2015. Revista Unemat de Contabilidade, 2017. v. 6, n. 11.

diretamente relacionadas ao cargo, tornando-se a "competência que o indivíduo mobiliza em face de uma situação profissional cada vez mais mutável e complexa". E o conceito de competência, segundo esses autores

é pensado como um conjunto de conhecimentos, habilidades e atitudes que justificam um alto desempenho, na medida em que há também um pressuposto de que os melhores desempenhos estão fundamentados na inteligência e na personalidade das pessoas. Nessa abordagem, considera-se a competência, portanto, como um estoque de recursos que o indivíduo detém (FLEURY; FLEURY, 2004, p. $45)$.

Brandão e Borges-Andrade (2007, p. 36) discutem a noção de competência a partir de diversos conceitos e concluem que é entendida "não apenas como um conjunto de conhecimentos, habilidades e atitudes necessários para exercer certa atividade, mas também como o desempenho expresso pela pessoa em determinado contexto, em termos de comportamentos adotados no trabalho e realizações decorrentes."

Cardoso, Riccio e Albuquerque (2009, p. 366), ressaltam que "o termo competência tem como origem a palavra competentia, do latim, que significa a qualidade de quem é capaz de apreciar e resolver certo assunto, de fazer determinada coisa, com capacidade, habilidade, aptidão e idoneidade".

Perante diversos conceitos, entende-se que, dentro de um determinado cenário, o qual possui suas necessidades, a competência significa utilizar conhecimentos, habilidades e atitudes com a intenção de atingir bom desempenho, ou seja, realizações e resultados que preencham as reinvindicações e que possam agregar valor a tal contexto.

\subsection{Competência para a Contabilidade no Brasil e no Mundo}

No Brasil, a Lei no 9.394, de 20 de dezembro de 1996 (BRASIL, 1996), estabelece que as Instituições de Ensino Superior devem "formar diplomados nas diferentes áreas de conhecimento, aptos para a inserção em setores profissionais e para a participação no desenvolvimento da sociedade brasileira, e colaborar na sua formação contínua". A partir disso, o Ministério da Educação e do Desporto (MEC), no ano de 1997, através do Parecer CNE/CES 776 (CNE; CES, 1997), convoca as Instituições de Ensino Superior a apresentarem propostas para as novas Diretrizes Curriculares Nacionais (DCN).

Um dos princípios fixados neste Parecer é que as Diretrizes Curriculares devem dar autonomia para as Instituições de Ensino Superior na definição dos currículos de seus cursos, propondo linhas gerais que possam expor as competências e habilidades a serem 
BARRESE, P. F.; BASTONI, T. R.; NOGUEIRA, D. R. Percepção sobre o desenvolvimento de competências profissionais no curso de ciências contábeis de acordo com o IAESB: uma análise com os egressos de 2011 a 2015. Revista Unemat de Contabilidade, 2017. v. 6, n. 11.

desenvolvidas.

Para o curso de Ciências Contábeis, após algumas alterações nos Pareceres, todos homologados pelo MEC, a Resolução CNE/CES n 10, de 16 de dezembro de 2004, institui as DCN e apresenta as capacitações, competências e habilidades mínimas da formação do profissional contábil, ficando a cargo da Instituição de Ensino Superior, na elaboração de seu Projeto Político Pedagódico (PPP), a admissão de "Linhas de Formação Específicas" dentre as áreas da Contabilidade.

Segundo esta Resolução, o Curso de Ciências Contábeis deve despertar as seguintes competências e habilidades em seus alunos durante o processo de formação:

I - utilizar adequadamente a terminologia e a linguagem das Ciências Contábeis e Atuariais;

II - demonstrar visão sistêmica e interdisciplinar da atividade contábil;

III - elaborar pareceres e relatórios que contribuam para o desempenho eficiente e eficaz de seus usuários, quaisquer que sejam os modelos organizacionais;

IV - aplicar adequadamente a legislação inerente às funções contábeis;

$\mathrm{V}$ - desenvolver, com motivação e através de permanente articulação, a liderança entre equipes multidisciplinares para a captação de insumos necessários aos controles técnicos, à geração e disseminação de informações contábeis, com reconhecido nível de precisão;

VI - exercer suas responsabilidades com o expressivo domínio das funções contábeis, incluindo noções de atividades atuariais e de quantificações de informações financeiras, patrimoniais e governamentais, que viabilizem aos agentes econômicos e aos administradores de qualquer segmento produtivo ou institucional o pleno cumprimento de seus encargos quanto ao gerenciamento, aos controles e à prestação de contas de sua gestão perante à sociedade, gerando também informações para a tomada de decisão, organização de atitudes e construção de valores orientados para a cidadania;

VII - desenvolver, analisar e implantar sistemas de informação contábil e de controle gerencial, revelando capacidade crítico analítica para avaliar as implicações organizacionais com a tecnologia da informação;

VIII - exercer com ética e proficiência as atribuições e prerrogativas que lhe são prescritas através da legislação específica, revelando domínios adequados aos diferentes modelos organizacionais. (CNE; CES, 2004)

No âmbito internacional, em 2014, o IAESB, órgão dedicado à elaboração de normas de educação na área de contabilidade, concluiu um projeto de reformulação e revisão dos IES, os quais abordam elementos importantes no processo de aprendizagem e desenvolvimento profissional. Na visão deste órgão, estabelecer os resultados de aprendizagem que devem ser desenvolvidos pelos aspirantes da contabilidade protege o interesse público, eleva a qualidade do trabalho dos profissionais contábeis e promove credibilidade da profissão contábil.

Após essa revisão, os IES foram delineados em 18 áreas de competência, contendo 82 resultados de aprendizagem, requeridos pelos futuros profissionais contábeis, que podem ser demonstrados dentro de um contexto de ambiente de trabalho. 
BARRESE, P. F.; BASTONI, T. R.; NOGUEIRA, D. R. Percepção sobre o desenvolvimento de competências profissionais no curso de ciências contábeis de acordo com o IAESB: uma análise com os egressos de 2011 a 2015. Revista Unemat de Contabilidade, 2017. v. 6, n. 11.

As áreas de competência que compõem o padrão $\mathrm{n}^{\circ} 2$ - Competências Técnicas (IAESB, 2014a) são: (a) Contabilidade e Relatórios Financeiros; (b) Contabilidade Gerencial; (c) Finanças e Gestão Financeira; (d) Tributação; (e) Auditoria e Asseguração; (f) Governança, Gerenciamento de Riscos e Controle Interno; (g) Leis e Regulamentações de Negócio; (h) Tecnologia da Informação; (i) Negócios e Ambiente Organizacional; (j) Economia; e (k) Estratégia e Gestão de Negócios.

Já o padrão $n^{\circ} 3$ apresenta as Habilidades Profissionais (IAESB, 2014b), que são segregadas da seguinte forma: (a) Intelectuais, as quais são relacionadas à capacidade de resolver problemas, tomar descisões e exercer julgamento profissional; (b) Interpessoais e Comunicação, ou seja, capacidade de trabalhar e interagir de maneira eficaz com os outros; (c) Pessoais, relacionam-se com as atitudes pessoais e comportamento; e (d) Organizacionais, associadas à aptidão em trabalhar eficazmente numa organização a fim de obter os melhores resultados, ou resultados das pessoas e recursos disponíveis.

Por fim, no padrão $\mathrm{n}^{\mathrm{o}}$ 4, em que são evidenciados os Valores, Ética e Atitudes Profissionais (IAESB, 2014c), as áreas de competência são divididas em: (a) Ceticismo e Julgamento Profissional, os quais estão relacionados a uma mentalidade e avaliação crítica, devendo estar sempre atento às condições que podem indicar distorção devido a erro ou fraude; (b) Princípios Éticos; e (c) Compromisso com o Interesse Público.

Além do IAESB, através de publicações do IFAC, outros órgãos internacionais dispõem de modelos de competências profissionais a serem apresentadas pelos profissionais contábeis, conforme citam Ott e Pires (2010) são eles: American Institute of Certified Public Accountants (AICPA), que divide em Competências Funcionais, Pessoais e Amplas Perspectivas sobre os Negócios; Accounting Education Change Commission (AECC), segmentando em Habilidades de Comunicação, Intelectuais e Interpessoais, além de Conhecimentos Gerais, Organizacionais e de Negócios, e de Contabilidade e Auditoria; e o Intergovernmental Working Group of Experts on International Standards os Accounting and Reporting / United Nations Conference on Trade and Development (ISAR/UNCTAD), que redigiu um guia nacional de requerimentos qualificação para profissionais contábeis.

Diante disso, Ott e Pires (2010) efetuaram uma análise comparativa da estrutura curricular do Curso de Ciências Contábeis no Brasil (Resolução CNE/CES nº 10/2004) com aquelas propostas por tais organismos internacionais e obtiveram, a partir da análise que, por mais que existam diferentes abordagens nas estruturas, elas encontram-se alinhadas entre si em relação ao conteúdo, o que demonstra uniformidade na maneira de direcionar o ensino 
BARRESE, P. F.; BASTONI, T. R.; NOGUEIRA, D. R. Percepção sobre o desenvolvimento de competências profissionais no curso de ciências contábeis de acordo com o IAESB: uma análise com os egressos de 2011 a 2015. Revista Unemat de Contabilidade, 2017. v. 6, n. 11.

contábil por parte destes órgãos.

\subsection{Pesquisas Recentes}

O estudo de Cardoso, Riccio e Albuquerque (2009), investigou as competências requeridas dos contadores, com ênfase na busca do entendimento da existência ou não de uma estrutura de interdependência subjacente às competências do Contador. $O$ resultado apresentou uma estrutura genérica de competências para o Contador: Competências de Articulação, Competências de Técnicas de Gestão, Competências de Conduta e Administração e Competências Específicas.

Em uma pesquisa realizada por Lemes (2013), buscou-se verificar o grau de importância que os profissionais da contabilidade que atuam no Triângulo Mineiro atribuem às habilidades preconizadas pelo IES 3, as quais estavam em um processo de revisão. Através de uma amostra de 126 profissionais da região, verificou-se alto nível de concordância em relação à importância das habilidades e, além disso, após uma análise fatorial, constatou-se aderência entre o que encontrava-se proposto pelo IES 3 e a realidade dos profissionais pesquisados. Portanto, a autora destaca que há necessidade de desenvolvimento dessas habilidades.

Reis et al. (2014) buscaram compreender qual a percepção dos discentes do Curso de Ciências Contábeis com relação às habilidades e competências necessárias para atuação do profissional contábil. A partir da análise dos dados, concluíram que, na percepção dos discentes, as habilidades intelectuais e do conhecimento, bem como as pessoais, são as mais importantes no âmbito profissional. Ainda segundo este estudo, as competências e habilidades apontadas também são as mais demandadas pelo mercado.

Oliveira e Silva (2014), realizaram uma pesquisa com o intuito de verificar o perfil do profissional contábil, de acordo com as habilidades estabelecidas pelo IFAC. Os autores puderam observar que os entrevistados possuíam familiaridade com as habilidades prescritas pelo IES 3 e julgavam deter níveis elevados de atendimento às habilidades definidas como relevantes pelo IFAC. Além disso, os autores destacam que, na opinião dos entrevistados, “a prática profissional contribuiu mais para o desenvolvimento de suas habilidades do que a graduação". Os autores ressaltam, ainda, que esta pesquisa possui limitações relacionadas à coleta de dados, uma vez que a avaliação se deu por meio da percepção do próprio profissional.

Nunes et al. (2014) também utilizando como base a IES 3, empenharam-se em 
BARRESE, P. F.; BASTONI, T. R.; NOGUEIRA, D. R. Percepção sobre o desenvolvimento de competências profissionais no curso de ciências contábeis de acordo com o IAESB: uma análise com os egressos de 2011 a 2015. Revista Unemat de Contabilidade, 2017. v. 6, n. 11.

identificar as habilidades e conhecimentos que os vestibulandos da região de Uberlândia-MG julgavam ser necessários para a atuação do contador. Os autores notaram que a percepção converge para muitas das habilidades descritas, principalmente àquelas técnicas e funcionais, porém constatou-se que os pesquisados não conhecem a amplitude da área de atuação do profissional e que isso pode afetar no momento escolha da profissão, pois existe um estereótipo de que o contador atua principalmente na área de exatas, intimidando aqueles que não gostam dessa área.

\section{ASPECTOS METODOLÓGICOS}

Quanto aos objetivos, a pesquisa pode ser classificada como descritiva, pois, segundo Gil (2010, p. 27), "as pesquisas descritivas têm como objetivo a descrição das características de determinada população". Do mesmo modo, Cooper e Schindler (2003, p. 136) destacam que os estudos descritivos atendem a diversos objetivos de pesquisa e, entre eles, citam as "descrições de fenômenos ou características associadas com a população-alvo".

Quanto aos procedimentos, a pesquisa classifica-se como levantamento ou survey, pois, de acordo com Gil (2010, p. 35), "procede-se à solicitação de informações a um grupo significativo de pessoas acerca do problema estudado para, em seguida, mediante análise quantitativa, obterem-se as conclusões correspondentes aos dados coletados".

A fim de atender o objetivo proposto, foram elaborados questionários eletrônicos (Google Docs), os quais foram enviados por e-mail aos egressos do Curso de Ciências Contábeis de uma Universidade Pública do Norte do Paraná que cursaram o último ano de graduação nos anos de 2011 a 2015.

Sendo assim, a abordagem do problema é quantitativa, pois busca identificar a percepção de uma determinada população em relação a um assunto, neste caso, a percepção dos egressos do Curso de Ciências Contábeis em relação ao desenvolvimento dos resultados de aprendizagem que o IAESB estabelece como relevantes para atingir a competência profissional, e, a partir disso, verificar quais são aquelas predominantes e as que necessitam de desenvolvimento durante o período de graduação.

O questionário foi dividido em quatro partes. A primeira parte constava o Termo de Consentimento Livre e Esclarecido, no qual estavam expostos esclarecimentos ao respondente a respeito da pesquisa. Na segunda parte, apresentavam-se 26 afirmativas contendo resultados de aprendizagem, retirados dos International Educational Standards 2 - Competência Técnica 
BARRESE, P. F.; BASTONI, T. R.; NOGUEIRA, D. R. Percepção sobre o desenvolvimento de competências profissionais no curso de ciências contábeis de acordo com o IAESB: uma análise com os egressos de 2011 a 2015. Revista Unemat de Contabilidade, 2017. v. 6, n. 11.

(IAEBS, 2014a), 3 - Habilidades Profissionais (IAESB, 2014b) e 4 - Valores, Ética e Atitudes

Profissionais (IAESB, 2014c); nesta parte as respostas estavam condicionadas à Escala Likert de 5 pontos, que variava de "Discordo Totalmente" a "Concordo Totalmente". A terceira parte buscava saber se o respondente desenvolveu os resultados de aprendizagem citados em outro ambiente diferente da universidade. E, por fim, a quarta parte atentou-se em informações a respeito dos egressos, como o ano de conclusão da graduação em Ciências Contábeis, o gênero, a idade e se o respondente está atuando na área.

\section{Quadro 1 - Afirmativas do questionário}

(continua)

\begin{tabular}{|c|c|}
\hline CT 1 & $\begin{array}{l}\text { Aplicar os princípios contábeis, as Normas Internacionais de Relatórios Financeiros (IFRSs) e outras } \\
\text { normas relevantes. }\end{array}$ \\
\hline CT 2 & $\begin{array}{l}\text { Preparar demonstrações financeiras, incluindo as demonstrações financeiras consolidadas, em } \\
\text { conformidade com as IFRSs ou outras normas relevantes. }\end{array}$ \\
\hline CT 3 & $\begin{array}{l}\text { Interpretar demonstrações financeiras, divulgações relacionadas e relatórios não financeiros e aplicar } \\
\text { técnicas de apoio a tomadas de decisão gerencial, além de preparar seus relatórios auxiliares. }\end{array}$ \\
\hline CT 4 & $\begin{array}{l}\text { Aplicar técnicas quantitativas para análise do comportamento do custo e seus condutores e avaliar } \\
\text { desempenho dos produtos e segmentos do negócio, além de preparar relatórios para auxiliar a tomada de } \\
\text { decisão gerencial. }\end{array}$ \\
\hline CT 5 & $\begin{array}{l}\text { Comparar as diversas fontes de financiamento disponíveis para uma organização visando o bom controle } \\
\text { do fluxo de caixa e necessidade de capital de giro da entidade, bem como sua posição financeira atual e } \\
\text { futura. }\end{array}$ \\
\hline CT 6 & $\begin{array}{l}\text { Explicar renda, com base em ativos, e abordagens de avaliação de mercado utilizadas para decisões de } \\
\text { investimento, planejamento de negócios e gestão financeira de longo prazo. }\end{array}$ \\
\hline CT 7 & $\begin{array}{l}\text { Explicar a tendência da tributação nacional, a diferença entre planejamento tributário, evasão fiscal e fraude } \\
\text { fiscal, assim como preparar cálculo de impostos diretos e indiretos para indivíduos e organizações. }\end{array}$ \\
\hline CT 8 & $\begin{array}{l}\text { Descrever os objetivos e etapas para a realização de uma auditoria de demonstrações financeiras, aplicar as } \\
\text { normas relevantes, leis e regulamentações. }\end{array}$ \\
\hline CT 9 & $\begin{array}{l}\text { Explicar os princípios de boa governança, analisar seus componentes dentro da estrutura de uma } \\
\text { organização e verificar os elementos do controle interno relacionados aos relatórios financeiros. }\end{array}$ \\
\hline CT 10 & $\begin{array}{l}\text { Explicar as leis e regulamentações que regem as diferentes formas de entidades jurídicas e as aplicáveis ao } \\
\text { ambiente em que os profissionais contábeis atuam. }\end{array}$ \\
\hline CT 11 & $\begin{array}{l}\text { Analisar a adequação dos controles gerais de tecnologia da informação, entendendo como ela contribui } \\
\text { para a análise de dados, e sua utilização como apoio à tomada de decisão. }\end{array}$ \\
\hline CT 12 & $\begin{array}{l}\text { Descrever o ambiente em que uma organização opera e analis ar aspectos do ambiente global que afetam o } \\
\text { comércio e as finanças internacionais. }\end{array}$ \\
\hline CT 13 & $\begin{array}{l}\text { Descrever os princípios fundamentais microeconômicos e macroeconômicos, bem como os efeitos das } \\
\text { mudanças nos indicadores macroeconômicos e explicar a diferença dos tipos de estrutura do mercado. }\end{array}$ \\
\hline CT 14 & $\begin{array}{l}\text { Explicar as formas que as organizações podem ser projetadas e estruturadas e a finalidade e importância das } \\
\text { áreas funcionais e operacionais dentro delas. }\end{array}$ \\
\hline CT 15 & $\begin{array}{l}\text { Explicar processos para a implementação de estratégias e analisar fatores externos e internos que podem } \\
\text { influenciar a estratégia de uma organização. }\end{array}$ \\
\hline CT 16 & $\begin{array}{l}\text { Explicar como teorias do comportamento organizacional podem ser usadas para elevar o desempenho do } \\
\text { indivíduo, das equipes e da organização. }\end{array}$ \\
\hline HP 1 & $\begin{array}{l}\text { Avaliar informação a partir da variedade de fontes e perspectivas através da investigação, análise e } \\
\text { integração. }\end{array}$ \\
\hline HP 2 & $\begin{array}{l}\text { Aplicar raciocínio, análise crítica e pensamento inovador para resolver problemas, recomendar soluções e } \\
\text { identificar quando é apropriado consultar especialistas para resolvê-los. }\end{array}$ \\
\hline HP 3 & $\begin{array}{l}\text { Demonstrar cooperação e trabalho em equipe, conhecimento de diferenças culturais e de linguagem e } \\
\text { comunicar-se de forma clara em situações formais e informais, tanto na escrita, quanto oralmente. }\end{array}$ \\
\hline
\end{tabular}


BARRESE, P. F.; BASTONI, T. R.; NOGUEIRA, D. R. Percepção sobre o desenvolvimento de competências profissionais no curso de ciências contábeis de acordo com o IAESB: uma análise com os egressos de 2011 a 2015. Revista Unemat de Contabilidade, 2017. v. 6, n. 11.

Quadro 1 - Afirmativas do questionário

\begin{tabular}{|l|l|}
\hline HP 4 & $\begin{array}{l}\text { Aplicar técnicas efetivas de entrevista e escutar ativamente, aplicar habilidades de negociação para atingir } \\
\text { soluções e acordos, habilidades consultivas para minimizar ou resolver conflitos e problemas, e maximizar } \\
\text { as oportunidades. }\end{array}$ \\
\hline HP 5 & $\begin{array}{l}\text { Demonstrar um compromisso com a aprendizagem, gerenciar tempo e recursos para alcançar compromis sos } \\
\text { profissionais, antecipar os desafios, planejar potenciais soluções e ter a mente aberta para novas } \\
\text { oportunidades. }\end{array}$ \\
\hline HP 6 & $\begin{array}{l}\text { Assumir funções em conformidade com as práticas estabelecidas para atender prazos previstos e avaliar o } \\
\text { próprio trabalho e dos outros para determinar se estão em conformidade com os padrões de qualidade da } \\
\text { organização. }\end{array}$ \\
\hline HP7 & Aplicar habilidades de gestão de pessoas, de delegação e de liderança. \\
\hline VE1 1 & $\begin{array}{l}\text { Senso crítico para avaliar informações financeiras e saber identificar e avaliar alternativas para chegar a } \\
\text { conclusões bem fundamentadas com base em fatos e circunstâncias. }\end{array}$ \\
\hline VE2 & $\begin{array}{l}\text { Explicar a natureza da ética, as vantagens e desvantagens de suas regras e princípios e explicar o papel da } \\
\text { ética dentro da profissão. }\end{array}$ \\
\hline VE3 & $\begin{array}{l}\text { Identificar problemas éticos e determinar quando e como aplicar os princípios éticos e exigências éticas, } \\
\text { lém de analisar condutas de alternativas de ação e determinar suas consequências, para a profis são e para } \\
\text { o público. }\end{array}$ \\
\hline
\end{tabular}

Fonte: Adaptado de International Educational Standards 2 (IAESB, 2014a), 3 (IAESB, 2014b) e 4 (IAESB, 2014c).

Destaca-se que o instrumento de coleta de dados (sentenças no Quadro 1) foi elaborado pelos pesquisadores com base nos itens dispostos nos IES 2, 3 e 4 (IAESB, 2014a; 2014b; 2014c) contudo, alguns itens foram suprimidos ou reduzidos para diminuir o número de sentenças, buscando assim elaborar um instrumento de coleta de dados que fosse amplo, abrangendo às áreas do IES, mas que não se tornasse demasiadamente longo e cansativo, desmotivando o aluno no preenchimento e prejudicando o processo de captação dos dados para a pesquisa.

Estes questionários foram submetidos a um pré-teste com 5 alunos do último ano de graduação em Ciências Contábeis e um profissional contábil, com o objetivo de identificar possíveis falhas quanto ao conteúdo que pretendia-se coletar. Na opinião de Gil (2010, p. 107), o pré-teste "está centrado na avaliação dos instrumentos enquanto tais, visando garantir que meçam exatamente o que pretendem medir."

Após os ajustes sugeridos, os questionários foram enviados aos egressos de 2011 a 2015, os quais totalizaram 420 e-mails válidos, ficando disponíveis aos egressos do dia 4/4/2016 ao dia 26/4/2016, obtendo-se 130 respostas, ou seja, 30,95\% de retorno, sendo que a maior porcentagem de retorno $(41,16 \%)$ foi dos concluintes de 2015 e a menor $(19,72 \%)$ foi a dos egressos de 2011. 
BARRESE, P. F.; BASTONI, T. R.; NOGUEIRA, D. R. Percepção sobre o desenvolvimento de competências profissionais no curso de ciências contábeis de acordo com o IAESB: uma análise com os egressos de 2011 a 2015. Revista Unemat de Contabilidade, 2017. v. 6, n. 11.

\begin{tabular}{|c|c|c|c|}
\hline Ano & $\begin{array}{l}\text { E-mails } \\
\text { Válidos }\end{array}$ & $\begin{array}{c}\text { Respostas } \\
\text { Obtidas }\end{array}$ & $\begin{array}{c}\% \\
\text { Retorno }\end{array}$ \\
\hline 2011 & 71 & 14 & $19,72 \%$ \\
\hline 2012 & 81 & 27 & $33,33 \%$ \\
\hline 2013 & 81 & 23 & $28,40 \%$ \\
\hline 2014 & 105 & 32 & $30,48 \%$ \\
\hline 2015 & 82 & 34 & $41,46 \%$ \\
\hline TOTAL & 420 & 130 & $30,95 \%$ \\
\hline
\end{tabular}

Fonte: Dados da Pesquisa.

Após a tabulação dos dados, procederam-se as análises descritivas e a análise de confiabilidade (Alpha de Cronbach). Esta última visando verificar se o constructo tinha adequada consistência interna, a qual indica o grau que os itens que compõem uma escala estão integrados e que refletem com consistência o constructo que estão medindo (PALLANT, 2005; FIELD, 2009).

Os Alphas obtidos foram: Competência Técnica $(0,919)$; Habilidades Profissionais $(0,911)$ e Valores, Ética e Atitudes Profissionais $(0,811)$. Assim, pode-se verificar que há uma boa consistência interna, visto que, segundo Field (2009), os valores mínimos considerados aceitáveis pela literatura são de 0,7 ou 0,8 , como os resultados ficaram acima deste valor, há evidências de consistência interna dos itens.

Quanto à normalidade da distribuição dos dados, foi realizado o teste de KolmogorovSmirnov, sendo que nenhuma das variáveis analisadas obteve distribuição normal dos dados, assim, utilizaram-se nos testes de comparação de média, os testes de Kruskal-Wallis e o teste U de Mann Whitney, que são, respectivamente, as versões não paramétricas para o teste ANOVA e independent $t$ test (PALLANT, 2005). Para a realização de tais testes, foi usado o programa Statistical Package for the Social Sciences (SPSS ${ }^{\circledR}$ ).

\section{APRESENTAÇÃO E ANÁLISE DOS DADOS}

\subsection{Perfil dos egressos}

Com relação ao perfil dos respondentes, analisou-se que pouco mais que a metade $(51,54 \%)$ é do gênero feminino, a idade dos respondentes varia de 21 anos a 46 anos, sendo que a maior frequência é dos discentes na faixa etária de 21 a 25 anos (49,23\%). Dos respondentes 73,08\% atuam na área contábil (Tabela 2). 
BARRESE, P. F.; BASTONI, T. R.; NOGUEIRA, D. R. Percepção sobre o desenvolvimento de competências profissionais no curso de ciências contábeis de acordo com o IAESB: uma análise com os egressos de 2011 a 2015. Revista Unemat de Contabilidade, 2017. v. 6, n. 11.

Tabela 2 - Perfil dos respondentes

\begin{tabular}{cccc}
\hline & & Qtde. & \% \\
\hline \multirow{2}{*}{ Gênero } & Feminino & 67 & $51,54 \%$ \\
& Masculino & 63 & $48,46 \%$ \\
\hline \multirow{4}{*}{ Idade } & 21 a 25 anos & 64 & $49,23 \%$ \\
& 26 a 30 anos & 42 & $32,31 \%$ \\
& 31 a 35 anos & 12 & $9,23 \%$ \\
& 36 a 40 anos & 5 & $3,85 \%$ \\
& 41 a 46 anos & 7 & $5,38 \%$ \\
\hline Atuando & Sim & 95 & $73,08 \%$ \\
na área & Não & 35 & $26,92 \%$ \\
\hline
\end{tabular}

Fonte: Dados da Pesquisa.

\subsection{Percepção do desenvolvimento de Competências}

Das 26 afirmativas, 16 apresentavam resultados de aprendizagem a respeito de Competência Técnica (IES 2), 7 de Habilidades Profissionais (IES 3) e 3 de Ética, Valores e Atitudes Profissionais (IES 4).

As respostas foram tabuladas em Excel e após quantificadas em porcentagem, obteve a média de respostas por grupo, as quais estão expostas na Tabela 3 e adiante serão descritas por questão.

Tabela 3 - Média das Respostas por IES

\begin{tabular}{|c|c|c|c|c|c|c|}
\hline & $\begin{array}{c}\text { Discordo } \\
\text { Totalmente }\end{array}$ & $\begin{array}{c}\text { Discordo } \\
\text { Parcialmente }\end{array}$ & $\begin{array}{c}\text { Não } \\
\text { Concordo, } \\
\text { Nem } \\
\text { Discordo }\end{array}$ & $\begin{array}{c}\text { Concordo } \\
\text { Parcialmente }\end{array}$ & $\begin{array}{l}\text { Concordo } \\
\text { Totalmente }\end{array}$ & TOTAL \\
\hline $\begin{array}{c}\text { IES 2- Competência } \\
\text { Técnica }\end{array}$ & $6,44 \%$ & $15,00 \%$ & $16,59 \%$ & $40,43 \%$ & $21,54 \%$ & $100,00 \%$ \\
\hline $\begin{array}{c}\text { IES } 3 \text { - Habilidades } \\
\text { Profissionais }\end{array}$ & $9,56 \%$ & $13,30 \%$ & $18,24 \%$ & $35,93 \%$ & $22,97 \%$ & $100,00 \%$ \\
\hline $\begin{array}{c}\text { IES } 4 \text { - Ética, Valores e } \\
\text { Atitudes Profissionais }\end{array}$ & $3,59 \%$ & $6,41 \%$ & $9,49 \%$ & $41,03 \%$ & $39,49 \%$ & $100,00 \%$ \\
\hline
\end{tabular}

Fonte: Dados da Pesquisa.

Ainda foi perguntado se outros ambientes possibilitaram o desenvolvimento das competências técnicas, habilidades profissionais, valores, ética e atitudes expostas no questionário e 125 respondentes colocaram que "Sim", ou seja, 96,15\% da amostra.

Destes outros ambientes citados, os que apareceram com mais frequência nas respostas foram, nesta ordem: ambiente de trabalho/profissional, estágio, cursos/treinamentos, ambiente familiar/sociedade em geral. Ainda foram citados congressos/palestras, desenvolvimento profissional (especialização, pós graduação, mestrado), notícias, veículos de informações, atividades extracurriculares, pesquisa/iniciação científica, entre outros. 
BARRESE, P. F.; BASTONI, T. R.; NOGUEIRA, D. R. Percepção sobre o desenvolvimento de competências profissionais no curso de ciências contábeis de acordo com o IAESB: uma análise com os egressos de 2011 a 2015. Revista Unemat de Contabilidade, 2017. v. 6, n. 11.

\subsubsection{Competência Técnica}

A seguir, apresenta-se o desdobramento das respostas obtidas apenas para as questões que compõem as Competências Técnicas. Como se pode observar, a maioria das questões tiveram maior percentual de respostas na afirmativa concordo parcialmente, demonstrando indícios de satisfação dos egressos com o ensino destas competências.

Tabela 4 - Percepção das Competências Técnicas

\begin{tabular}{cccccc}
\hline Questões & $\begin{array}{c}\text { Discordo } \\
\text { Totalmente }\end{array}$ & $\begin{array}{c}\text { Discordo } \\
\text { Parcialmente }\end{array}$ & $\begin{array}{c}\text { Não concordo, } \\
\text { nem discordo }\end{array}$ & $\begin{array}{c}\text { Concordo } \\
\text { Parcialmente }\end{array}$ & $\begin{array}{c}\text { Concordo } \\
\text { Totalmente }\end{array}$ \\
\hline CT 1 & $1,54 \%$ & $6,15 \%$ & $1,54 \%$ & $51,54 \%$ & $39,23 \%$ \\
CT 2 & $2,31 \%$ & $6,15 \%$ & $1,54 \%$ & $50,77 \%$ & $39,23 \%$ \\
CT 3 & $1,54 \%$ & $7,69 \%$ & $4,62 \%$ & $42,31 \%$ & $43,85 \%$ \\
CT 4 & $3,85 \%$ & $8,46 \%$ & $14,62 \%$ & $47,69 \%$ & $25,38 \%$ \\
CT 5 & $8,46 \%$ & $16,15 \%$ & $17,69 \%$ & $39,23 \%$ & $18,46 \%$ \\
CT 6 & $6,92 \%$ & $14,62 \%$ & $17,69 \%$ & $46,92 \%$ & $13,85 \%$ \\
CT 7 & $6,15 \%$ & $16,92 \%$ & $20,00 \%$ & $33,08 \%$ & $23,85 \%$ \\
CT 8 & $6,92 \%$ & $11,54 \%$ & $13,85 \%$ & $46,92 \%$ & $20,77 \%$ \\
CT 9 & $5,38 \%$ & $16,92 \%$ & $22,31 \%$ & $37,69 \%$ & $17,69 \%$ \\
CT 10 & $4,62 \%$ & $19,23 \%$ & $18,46 \%$ & $36,15 \%$ & $21,54 \%$ \\
CT 11 & $11,54 \%$ & $16,15 \%$ & $16,92 \%$ & $40,77 \%$ & $14,62 \%$ \\
CT 12 & $7,69 \%$ & $21,54 \%$ & $23,08 \%$ & $36,92 \%$ & $10,77 \%$ \\
CT 13 & $14,62 \%$ & $23,08 \%$ & $23,85 \%$ & $28,46 \%$ & $10,00 \%$ \\
CT 14 & $3,85 \%$ & $13,08 \%$ & $25,38 \%$ & $39,23 \%$ & $18,46 \%$ \\
CT 15 & $6,92 \%$ & $17,69 \%$ & $20,77 \%$ & $40,77 \%$ & $13,85 \%$ \\
CT 16 & $10,77 \%$ & $24,62 \%$ & $23,08 \%$ & $28,46 \%$ & $13,08 \%$ \\
\hline
\end{tabular}

Fonte: Dados da Pesquisa.

Tratando-se do IES 2 Competências Técnicas, as questões que estão relacionadas a Contabilidade e Relatórios Financeiros (CT 1 e CT 2) mostraram que mais de $90 \%$ dos respondentes concordam parcialmente ou totalmente com as afirmativas, sendo que ambas as questões ultrapassaram 50\% na resposta "Concordo Parcialmente".

O percentual de respondentes que concordam parcialmente ou totalmente na questão que aborda Contabilidade e Relatórios Financeiros e Contabilidade Gerencial (CT 3) foi de 86,16\%. Esta foi a única questão do padrão de Competência Técnica que obteve maior percentual na resposta "Concordo Totalmente".

Mais adiante, quando somente é abordado o assunto de Contabilidade Gerencial (CT 4), o percentual dos respondentes que concordam parcialmente ou totalmente cai para $73,07 \%$, sendo que o terceiro percentual mais alto nessa questão $(14,62 \%)$ ficou na resposta de "Não concordo, nem discordo".

Na primeira questão contendo itens de Finanças e Gestão Financeira (CT 5), 39,23\% dos egressos responderam "Concordo Parcialmente", 18,46\% "Concordo Totalmente", 
BARRESE, P. F.; BASTONI, T. R.; NOGUEIRA, D. R. Percepção sobre o desenvolvimento de competências profissionais no curso de ciências contábeis de acordo com o IAESB: uma análise com os egressos de 2011 a 2015. Revista Unemat de Contabilidade, 2017. v. 6, n. 11.

17,69\% "Não concordo, nem discordo" e 16,15\% "Discordo Parcialmente". Na segunda questão (CT 6), o percentual de respondentes que concordam parcialmente aumentou para $46,92 \%$, aqueles que concordam totalmente diminuiu para $13,85 \%$, juntamente com as respostas "Discordo Parcialmente" que apresentou o percentual de 14,62\%; já as respostas "Não concordo, nem discordo" permaneceram com o mesmo percentual.

A questão sobre Tributação (CT 7), obteve maior percentual dos respondentes que concordam parcialmente, totalizando $33,08 \%$ das respostas. Aqueles que concordam totalmente foram $23,85 \%$ e, em seguida, "Não concordo, nem discordo" ficou com o percentual de $20 \%$; os que discordam parcialmente totalizaram $16,92 \%$.

Na questão de Auditoria e Asseguração (CT 8), 67,69\% dos respondentes concordam parcialmente ou totalmente que foram preparados para descrever os objetivos e etapas para a realização de uma auditoria de demonstrações financeiras, aplicar as normas relevantes, leis e regulamentações.

A respeito de Governança, Gerenciamento de Riscos e Controle Interno (CT 9), $37,69 \%$ concorda parcialmente que foi preparado para os resultados citados, $22,31 \%$ das respostas indicou neutralidade ou indecisão, 17,69\% respondeu que concorda totalmente e $16,92 \%$ que discorda parcialmente.

A questão que apresenta os resultados de aprendizagem sobre a área de Leis e Regulamentação de Negócio (CT 10) mostra que 36,15\% acredita que foi preparado para as situações expostas, mas não totalmente, $21,54 \%$ concorda totalmente, $19,23 \%$ discorda parcialmente e $8,46 \%$ responderam "não concordo, nem discordo".

Sobre os resultados de Tecnologia da Informação (CT 11), 40,77\% concorda parcialmente, seguido do percentual que indica neutralidade ou indecisão, que foi de 16,92\%, logo adiante aqueles que discordam parcialmente, totalizando $16,15 \%$ e, posteriormente, os que concordam totalmente foram $14,62 \%$.

$\mathrm{Na}$ área de competência que descreve Negócios e Ambiente Organizacional (CT 12), $36,92 \%$ concorda parcialmente com os resultados de aprendizagem citados, 23,08\% respondeu que não concorda, nem discorda, $21,54 \%$ discorda parcialmente e, com uma grande diferença, aqueles que concordam totalmente totalizaram em 10,77\% dos respondentes.

Sobre Economia (CT 13), 38,46\% dos repondentes concordam parcialmente ou totalmente que foram preparados para descrever os princípios fundamentais microeconômicos e macroeconômicos, bem como os efeitos das mudanças nos indicadores macroeconômicos e explicar a diferença dos tipos de estrutura do mercado, enquanto 37,69\% discordam 
BARRESE, P. F.; BASTONI, T. R.; NOGUEIRA, D. R. Percepção sobre o desenvolvimento de competências profissionais no curso de ciências contábeis de acordo com o IAESB: uma análise com os egressos de 2011 a 2015. Revista Unemat de Contabilidade, 2017. v. 6, n. 11.

totalmente ou parcialmente.

As 3 questões a respeito de Estratégia e Gestão de Negócios apresentam maior percentual dos respondentes daqueles que concordam parcialmente. A primeira (CT 14), que afirma se o respondente foi preparado para explicar as formas que as organizações podem ser projetadas e estruturadas e a finalidade e importância das áreas funcionais e operacionais dentro delas, obteve $39,23 \%$ de respostas que concordam parcialmente, $25,38 \%$ dos respondentes mostraram indecisão ou neutralidade, seguido de 18,46\% que concordam totalmente com o que está exposto na afirmativa, por fim 16,92\% discordam parcialmente ou totalmente.

A segunda questão (CT 15), a qual visava saber se o egresso foi preparado para explicar processos para a implementação de estratégias e analisar fatores externos e internos que podem influenciar a estratégia de uma organização, 54,62\% respondeu que concorda parcialmente ou totalmente, $24,62 \%$ que discorda parcialmente ou totalmente e $20,77 \%$ colocou que não concorda, nem discorda que foi preparado para esse tipo de situação.

Na última questão de Estratégia e Gestão de Negócios (CT 16) e também do conteúdo sobre Competência Técnica, 41,54\% afirmou que concorda parcialmente ou totalmente que foi preparado para explicar como teorias do comportamento organizacional podem ser usadas para elevar o desempenho do indivíduo, das equipes e da organização, 35,38\% discorda parcialmente ou totalmente e $23,08 \%$ indicou neutralidade ou indecisão.

Em geral, as áreas de competência que obtiveram maior percentual de concordância (parcialmente e totalmente) foram Contabilidade e Relatórios Financeiros e Contabilidade Gerencial, portanto há evidências de que o conteúdo foi bem absorvido durante o período de graduação. Já as áreas que obtiveram menor percentual de concordância foram Negócios e Ambiente Organizacional, Economia e Estratégia e Gestão de Negócios, mostrando indícios de que estes conteúdos não foram bem desenvolvidos, o que não quer dizer que eles não foram passados pela universidade.

\subsubsection{Habilidades Profissionais}

Ao analisar a Tabela 5 pode-se verificar que a maior parte dos egressos concordam parcialmente na maior parte das questões sobre habilidades profissionais, demonstrando assim uma relativa satisfação com as habilidades ensinadas no período de graduação. 
BARRESE, P. F.; BASTONI, T. R.; NOGUEIRA, D. R. Percepção sobre o desenvolvimento de competências profissionais no curso de ciências contábeis de acordo com o IAESB: uma análise com os egressos de 2011 a 2015. Revista Unemat de Contabilidade, 2017. v. 6, n. 11.

\begin{tabular}{cccccc}
\hline \multicolumn{5}{c}{ Tabela 5 - Percepção das Habilidades Profissionais } \\
\hline Questões & $\begin{array}{c}\text { Discordo } \\
\text { Totalmente }\end{array}$ & $\begin{array}{c}\text { Discordo } \\
\text { Parcialmente }\end{array}$ & $\begin{array}{c}\text { Não concordo, } \\
\text { nem discordo }\end{array}$ & $\begin{array}{c}\text { Concordo } \\
\text { Parcialmente }\end{array}$ & $\begin{array}{c}\text { Concordo } \\
\text { Totalmente }\end{array}$ \\
\hline HP 1 & $8,46 \%$ & $12,31 \%$ & $24,62 \%$ & $40,00 \%$ & $14,62 \%$ \\
HP 2 & $8,46 \%$ & $7,69 \%$ & $18,46 \%$ & $38,46 \%$ & $26,92 \%$ \\
HP 3 & $6,15 \%$ & $10,77 \%$ & $16,92 \%$ & $30,77 \%$ & $35,38 \%$ \\
HP 4 & $19,23 \%$ & $21,54 \%$ & $18,46 \%$ & $28,46 \%$ & $12,31 \%$ \\
HP 5 & $5,38 \%$ & $10,77 \%$ & $19,23 \%$ & $37,69 \%$ & $26,92 \%$ \\
HP 6 & $3,08 \%$ & $10,77 \%$ & $14,62 \%$ & $43,08 \%$ & $28,46 \%$ \\
HP 7 & $16,15 \%$ & $19,23 \%$ & $15,38 \%$ & $33,08 \%$ & $16,15 \%$ \\
\hline
\end{tabular}

Fonte: Dados da Pesquisa.

As duas primeiras questões deste bloco, compreendem os resultados de aprendizagem da área de competência sobre habilidade Intelectual. Na primeira (HP 1), 40\% dos respondentes colocaram que concordam parcialmente, seguido de 24,62\% que não concordam, nem discordam, 14,62\% que concordam totalmente e 12,31\% que discordam parcialmente.

Na segunda questão (HP 2), 65,38\% concordam parcialmente ou totalmente, 18,46\% indicaram neutralidade ou indecisão, seguido por $16,15 \%$ que discordam parcialmente ou totalmente que foi preparado para aplicar raciocínio, análise crítica e pensamento inovador para resolver problemas, recomendar soluções e identificar quando é apropriado consultar especialistas para resolvê-los.

A seguir, foram apresentadas duas questões a respeito da área de competência "Interpessoal e Comunicação". Portanto, a terceira questão (HP 3) relacionada ao IES 3 (IAESB) demonstrou que $66,15 \%$ concordam parcialmente ou totalmente com o resultado de aprendizagem colocado, sendo que desse percentual o maior foi que concordavam totalmente $(35,38 \%)$. Daqueles que afirmaram indecisão ou neutralidade, obtiveram o percentual de $16,92 \%$, assim como os que discordaram parcialmente ou totalmente.

A quarta questão (HP 4) obteve o mesmo percentual $(40,77 \%)$ para aqueles que concordaram parcialmente ou totalmente e aqueles que discordaram parcialmente ou totalmente. Entretanto, os respondentes que discordam totalmente $(19,23 \%)$ atingiram maior percentual aos que concordam totalmente $(12,31 \%)$.

Os resultados de aprendizagem da área de competência denominada "Pessoal" (HP 5) obteve $64,62 \%$ de respondentes que concordam totalmente ou parcialmente, seguido de $19,23 \%$ daqueles que indicaram neutralidade ou indecisão e 16,15\% que discordaram parcialmente ou totalmente.

As duas últimas questões deste bloco estão relacionadas à área de Habilidades Organizacionais, sendo que a primeira (HP 6) obteve o maior percentual de concordância, seja 
BARRESE, P. F.; BASTONI, T. R.; NOGUEIRA, D. R. Percepção sobre o desenvolvimento de competências profissionais no curso de ciências contábeis de acordo com o IAESB: uma análise com os egressos de 2011 a 2015. Revista Unemat de Contabilidade, 2017. v. 6, n. 11.

parcialmente, ou totalmente, totalizando $71,54 \%$ das respostas. Em seguida vêm aqueles que não concordam nem discordam $(14,62 \%)$ e, logo após, com 13,85\%, aqueles que discordam parcialmente ou totalmente.

Na última questão (HP 7), obteve-se o mesmo percentual para aqueles que concordam totalmente e aqueles que discordam totalmente, que foi de $16,15 \%$. O maior percentual dessa questão foi de $33,08 \%$, correspondente àqueles que concordam parcialmente e, em seguida, aqueles que discordam parcialmente, os quais obtiveram o percentual de 19,23\%.

Conforme os resultados apresentados, a questão que apresentou maior percentual de concordância foi aquela que consta alguns aspectos da área de competência Organizacional, mostrando indícios de que os egressos aprenderam a atender os prazos e avaliar o trabalho para determinar se estão em conformidade com os padrões da organização. Em contrapartida, o menor percentual apresentado foi com relação à área Interpessoal e de Comunicação.

\subsubsection{Valores, Ética e Atitudes Profissionais}

No último bloco, ao analisar as questões sobre Valores, Ética e Atitudes Profissionais, oriundas do IES 4, pode-se verificar novamente uma maior frequência de respostas nas afirmativas concordo parcialmente e mais especificamente na VE2 $50 \%$ dos estudantes assinalando concordo totalmente.

Tabela 6 - Percepção dos Valores, Ética e Atitudes Profissionais

\begin{tabular}{cccccc}
\hline Questões & $\begin{array}{c}\text { Discordo } \\
\text { Totalmente }\end{array}$ & $\begin{array}{c}\text { Discordo } \\
\text { Parcialmente }\end{array}$ & $\begin{array}{c}\text { Não concordo, } \\
\text { nem discordo }\end{array}$ & $\begin{array}{c}\text { Concordo } \\
\text { Parcialmente }\end{array}$ & $\begin{array}{c}\text { Concordo } \\
\text { Totalmente }\end{array}$ \\
\hline VE 1 & $5,38 \%$ & $7,69 \%$ & $13,85 \%$ & $44,62 \%$ & $28,46 \%$ \\
VE 2 & $2,31 \%$ & $6,92 \%$ & $5,38 \%$ & $35,38 \%$ & $50,00 \%$ \\
VE 3 & $3,08 \%$ & $4,62 \%$ & $9,23 \%$ & $43,08 \%$ & $40,00 \%$ \\
\hline
\end{tabular}

Fonte: Dados da Pesquisa.

A primeira questão do IES 4, apresentou os resultados de aprendizagem a respeito da área de competência de Ceticismo e Julgamento Profissional (VE 1) e obteve o seguinte resultado: $73,08 \%$ dos respondentes concordaram parcialmente ou totalmente, seguido de $13,85 \%$ que não concorda, nem discorda que foi preparado para as situações citadas, enquanto $13,08 \%$ discordam parcialmente ou totalmente.

As outras questões englobam as áreas de competência sobre Princípios Éticos e Compromisso com o Interesse Público. Na primeira questão sobre essas áreas (VE 2), a qual obteve o maior percentual daqueles que concordam totalmente $(50 \%)$, os respondentes deveriam colocar se foram preparados para explicar a natureza da ética, as vantagens e 
BARRESE, P. F.; BASTONI, T. R.; NOGUEIRA, D. R. Percepção sobre o desenvolvimento de competências profissionais no curso de ciências contábeis de acordo com o IAESB: uma análise com os egressos de 2011 a 2015. Revista Unemat de Contabilidade, 2017. v. 6, n. 11.

desvantagens de suas regras e princípios e explicar o papel da ética dentro da profissão. O segundo maior percentual foi de respondentes que concordam parcialmente, que totalizaram $35,38 \%$.

Na segunda questão sobre Princípios Éticos e Compromisso com o Interesse Público (VE 3) e a última do IES 4 (IAESB), 83,08\% concordam parcialmente ou totalmente que foram preparados para identificar problemas éticos e determinar quando e como aplicar os princípios éticos e exigências éticas, além de analisar condutas de alternativas de ação e determinar suas consequências, para a profissão e o para o público, 9,23\% indicou neutralidade ou indecisão a respeito desses resultados de aprendizagem, e 7,69\% indicou que discorda parcialmente ou totalmente.

Diante do alto percentual de concordância nas questões do IES 4 (IAESB), há evidências de que os Valores, Ética e Atitudes Profissionais foram bem desenvolvidos durante o período de graduação, sendo dentro da universidade ou mesmo nos outros ambientes citados pelos egressos.

\subsection{Análise Estatística}

Visando comparar as turmas e verificar se havia alguma diferença na percepção de aprendizado das Competências pelos egressos nos diferentes anos, realizou-se testes de diferença de médias (Kruskal-Wallis) entre as turmas (2011 a 2015).

Após a realização do teste de diferença de média com todas as variáveis, pode-se verificar que apenas uma variável (CT 7 - Explicar a tendência da tributação nacional, a diferença entre planejamento tributário, evasão fiscal e fraude fiscal, assim como preparar cálculo de impostos diretos e indiretos para indivíduos e organizações) apresentou diferença nos scores quando comparados os anos de formação, visto que sig < 0,05 (Tabela 8).

Quando analisado a comparação ano por ano de formação pode-se verificar que na questão CT 7 houve diferença na média das opiniões das turmas de 2012 com as turmas de 2014 ( Sig. $=0,002)$ e 2015 ( Sig. $=0,003$ ) e também da turma de 2013 com a turma de 2015 (Sig. = 0,041). Portanto, há indícios que, na opinião dos egressos, o assunto foi abordado com maior amplitude na turma de 2012 do que nas turmas de 2014 e 2015 e a turma de 2013 em relação à turma de 2015. 
BARRESE, P. F.; BASTONI, T. R.; NOGUEIRA, D. R. Percepção sobre o desenvolvimento de competências profissionais no curso de ciências contábeis de acordo com o IAESB: uma análise com os egressos de 2011 a 2015. Revista Unemat de Contabilidade, 2017. v. 6, n. 11.

\begin{tabular}{|c|c|c|c|}
\hline Tabela 7 & Post & $\mathrm{de}$ & Média Respos \\
\hline & Ano & $\mathbf{N}$ & Postos de média \\
\hline & 2011 & 14 & 73,50 \\
\hline & 2012 & 27 & 81,78 \\
\hline СТ7 & 2013 & 23 & 74,11 \\
\hline (1) & 2014 & 32 & 55,98 \\
\hline & 2015 & 34 & 52,41 \\
\hline & Total & 130 & \\
\hline
\end{tabular}

Fonte: Dados da Pesquisa.

Tabela 8 - Estatísticas do Teste de Kruskal Wallis

\begin{tabular}{lr}
\hline \multicolumn{2}{c}{ CT7 } \\
\hline Qui-quadrado & 13,891 \\
df & 4 \\
Significância Sig. &, 008 \\
\hline \multicolumn{2}{c}{ a. Teste Kruskal Wallis } \\
b. Variável de Agrupamento: ano grad
\end{tabular}

Fonte: Dados da Pesquisa.

Mediante este resultado, procurou-se alguns professores do departamento tentando compreender o que poderia influenciar, segundo relatos dos docentes, houve uma alteração no Projeto Político Pedagógico (PPP), assim, os formandos em 2012 eram a última turma do projeto antigo e a partir de 2013 eram formadas as turmas do novo PPP.

Ciente dessa variável que poderia impactar nas análises, procedeu-se a um teste de diferença de média entre dois grupos (PPP Antigo e Novo). Diante da comparação entre os alunos que se formaram em projetos políticos pedagógicos diferentes, as variáveis que apresentaram diferença de média (Tabela 10) foram CT 3 (Sig. 0,040), CT 4 (Sig. 0,042) e CT 7 (Sig. 0,004).

Observando a Tabela 9, verifica-se que os alunos do PPP antigo atribuíam maiores scores de concordância com as 3 variáveis (CT3, CT4 e CT7) do que os alunos do PPP novo, o que pode demonstrar indícios de que os conteúdos de Processo Decisorial (Contabilidade Gerencial), Técnicas de Contabilidade de Custos e Tributação são pontos que merecem ser discutidos pelos gestores do curso visando implementar melhoria nestas disciplinas/conteúdos. 
BARRESE, P. F.; BASTONI, T. R.; NOGUEIRA, D. R. Percepção sobre o desenvolvimento de competências profissionais no curso de ciências contábeis de acordo com o IAESB: uma análise com os egressos de 2011 a 2015. Revista Unemat de Contabilidade, 2017. v. 6, n. 11.

\begin{tabular}{ccccc}
\multicolumn{4}{c}{ Tabela 9 - Projeto Pedagógico } \\
\hline \multirow{4}{*}{ PPC } & N & $\begin{array}{c}\text { Postos de } \\
\text { média }\end{array}$ & $\begin{array}{c}\text { Soma de } \\
\text { Classificações }\end{array}$ \\
\hline \multirow{4}{*}{ CT4 } & Antigo & 41 & 74,68 & 3062,00 \\
& Novo & 89 & 61,27 & 5453,00 \\
& Total & 130 & & \\
\hline \multirow{4}{*}{ CT7 } & Novo & 41 & 74,73 & 3064,00 \\
& Total & 130 & 61,25 & 5451,00 \\
& Antigo & 41 & 78,95 & 3237,00 \\
& Novo & 89 & 59,30 & 5278,00 \\
& Total & 130 & & \\
\hline
\end{tabular}

Fonte: Dados da Pesquisa.

Tabela 10 - Estatísticas do Teste de Mann-Whitney

\begin{tabular}{lrrr}
\hline & CT3 & \multicolumn{1}{c}{ CT4 } & \multicolumn{1}{c}{ CT7 } \\
\hline U de Mann-Whitney & 1448,000 & 1446,000 & 1273,000 \\
Wilcoxon W & 5453,000 & 5451,000 & 5278,000 \\
Z & $-2,059$ & $-2,032$ & $-2,854$ \\
Significância Sig. (2 extremidades) &, 040 &, 042 &, 004 \\
\hline \multicolumn{4}{c}{ a. Variável de Agrupamento: PPC_Antigo_novo } \\
Fonte: Dados da Pesquisa.
\end{tabular}

\section{CONSIDERAÇÕES FINAIS}

Diante do objetivo de identificar a percepção do egresso do Curso de Ciências Contábeis em relação ao desenvolvimento dos resultados de aprendizagem que o IAESB estabelece como relevantes para atingir a competência profissional durante o período de graduação, realizou-se uma pesquisa descritiva com os egressos de 2011 a 2015 de uma universidade pública paranaense.

$\mathrm{Na}$ identificação do perfil dos respondentes, observou-se que 51,54\% são do gênero e as idades variam de 21 a 46 anos, sendo que o maior percentual é o da faixa etária de 21 a 25 $\operatorname{anos}(49,23 \%)$.

As questões a respeito dos IES 2, 3 e 4 estavam divididas em 3 grupos: IES 2 Competência Técnica (IAESB, 2014a); IES 3 - Habilidades Profissionais (IAESB, 2014b); e IAS 4 - Valores, Ética e Atitudes Profissionais (IAESB, 2014c). Os dados coletados apontaram que, durante o curso de graduação, as competências relacionadas ao desenvolvimento dos Valores, Ética e Atitudes Profissionais, obtiveram maior percentual de concordância (parcialmente e totalmente), portanto, há evidências de que foram mais bem absorvidas $(80,52 \%)$. Em contrapartida, o menor percentual de concordância apontado pelos egressos, foi com relação às Habilidades Profissionais $(58,90 \%)$. 
BARRESE, P. F.; BASTONI, T. R.; NOGUEIRA, D. R. Percepção sobre o desenvolvimento de competências profissionais no curso de ciências contábeis de acordo com o IAESB: uma análise com os egressos de 2011 a 2015. Revista Unemat de Contabilidade, 2017. v. 6, n. 11.

Ainda é possível observar que, embora a questão sobre tributação (CT 7) tenha obtido percentual de concordância de 56,92\%, esta foi a única questão que apresentou diferença de média quando comparados os anos de formação, mostrando que as turmas de 2012 e 2013 tem níveis superiores de concordância sobre terem desenvolvido essa competência técnica do que as turmas formadas nos anos de 2014 e 2015.

Outro ponto observado no estudo foi que houve diferenças em algumas questões (CT 3, CT 4 e CT 7) na comparação dos egressos que cursaram a graduação no projeto pedagógico antigo (2011 e 2012) e o novo (2013, 2014 e 2015). Nesta análise, notou-se maior concordância nestas questões daqueles que cursaram a graduação durante o projeto pedagógico antigo, sendo que os egressos do PPP novo atribuíam menores escores para estes conteúdos.

Conforme a pesquisa de Reis et al. (2014), é destacado que as competências mais importantes na visão dos discentes são as habilidades intelectuais e do conhecimento e as pessoais, além de serem as mais demandadas pelo mercado de trabalho. Na presente pesquisa, a questão sobre a área de competência das Habilidades Intelectuais também obteve percentual de concordância de 54,62\% e a questão sobre as Habilidades Pessoais obteve 64,62\% de concordância.

Segundo a pesquisa de Oliveira e Silva (2014), os entrevistados julgaram que a prática profissional contribuiu mais para com o desenvolvimento das habilidades (IES 3, 2012) do que somente a graduação. De acordo com o presente estudo, 96,15\% dos respondentes acreditam que outros ambientes possibilitaram o desenvolvimento das competências profissionais citadas nesta pesquisa, sendo que o ambiente de trabalho/profissional foi aquele mencionado com maior frequência.

No geral, observa-se, ainda, um grande percentual de respostas "Concordo Parcialmente", isto posto, entende-se que grande parte dos resultados de aprendizagem foram desenvolvidos de forma satisfatória na percepção dos egressos. Em complemento, como $73,08 \%$ dos respondentes estão atuando na área, infere-se que, por mais que o desenvolvimento não tenha sido completo, é suficiente para que o discente esteja apto a atuar no mercado de trabalho.

Os resultados da pesquisa foram repassados à Coordenação do Curso e Colegiado, visando assim contribuir com informações para o processo de análise e, se necessário, alteração do Projeto Político Pedagógico do Curso. 
BARRESE, P. F.; BASTONI, T. R.; NOGUEIRA, D. R. Percepção sobre o desenvolvimento de competências profissionais no curso de ciências contábeis de acordo com o IAESB: uma análise com os egressos de 2011 a 2015. Revista Unemat de Contabilidade, 2017. v. 6, n. 11.

Os resultados da pesquisa devem ser observados considerando algumas limitações, sendo elas: As análises são baseadas apenas na percepção dos discentes egressos, não foram realizadas análises com os estudantes atuais do curso; procedimento de sintetização de algumas variáveis do IES 2, 3 e 4 na elaboração do instrumento de coleta de dados; análise realizada em período relativamente curto de 5 anos.

Sugere-se que, para pesquisas futuras, a amostra seja ampliada ou alterada, pesquisando Instituições de Ensino Superior de outras cidades, estados ou países, visto que este standard tem alcance mundial. Outras pesquisas podem também buscar avaliar o desenvolvimento destas competências com pesquisas de enfoque qualitativos, analisando casos em profundidade. Pesquisas que tentem correlacionar o desenvolvimento dessas competências e o impacto na carreira dos egressos do curso ou nos scores de desempenho do curso em exames nacionais também são bem vindas.

\section{REFERÊNCIAS}

BRANDÃO, H. P.; BORGES-ANDRADE, J. E. Causas e efeitos da expressão de competências no trabalho: para entender melhor a noção de competência. Revista de Administração Mackenzie, v. 8, n. 3, jul-set, 2007.

BRASIL. Lei de Diretrizes e Bases da Educação Nacional. Lei número 9394, 20 de dezembro de 1996. Estabelece as diretrizes e bases da educação nacional. Brasília: Ministério da Educação. 1996. Disponível em: <https://www.planalto.gov.br/ccivil_03/Leis/L9394.htm>. Acesso em: 17 de setembro de 2015.

BRASIL. Ministério da Educação. Edital SESu/MEC No 4/97. Brasília: Edital SESu/MEC. 1997. Disponível em: <http://portal.mec.gov.br/sesu/arquivos/pdf/e04.pdf>. Acesso em: jan. 2016.

CARDOSO, R.L.; RICCIO, E.L.; ALBUQUERQUE, L.G. Competências do contador: um estudo sobre a existência de uma estrutura de interdependência. Revista de Administração da Universidade de São Paulo, São Paulo, v.44, n.4, p.365-379, out./nov./dez. 2009.

CONSELHO NACIONAL DE EDUCAÇÃO - CNE; CÂMARA DE EDUCAÇÃO SUPERIOR - CES. Parecer CNE $\mathbf{n}^{\mathbf{0}}$ 776. Orienta para as Diretrizes Curriculares dos cursos de graduação. Brasília: CNE, 1997.

CONSELHO NACIONAL DE EDUCAÇÃO - CNE; CÂMARA DE EDUCAÇÃO SUPERIOR - CES. Resolução CNE/CES 10, de 16 de Dezembro de 2004. Institui as Diretrizes Nacionais para o Curso de Graduação em Ciências Contábeis, bacharelado, e dá outras providências. Brasília: CNE/CES, 2004. Disponível em: <http://portal.mec.gov.br/cne/arquivos/pdf/rces10_04.pdf>. Acesso em 15 setembro de 2015.

COOPER, D. R.; SCHINDLER, P. S. Métodos de Pesquisa em Administração. 7. ed. Porto Alegre: Bookkman, 2003. 
BARRESE, P. F.; BASTONI, T. R.; NOGUEIRA, D. R. Percepção sobre o desenvolvimento de competências profissionais no curso de ciências contábeis de acordo com o IAESB: uma análise com os egressos de 2011 a 2015. Revista Unemat de Contabilidade, 2017. v. 6, n. 11.

FIELD, A. Descobrindo a Estatística usando o SPSS. 2. ed. Porto Alegre: Artmed, 2009.

FLEURY, M. T. L.; FLEURY, A. C. C. Alinhando Estratégia e Competências. Revista de Administração de Empresas, v. 44, n. 1, jan-mar, p. 44-57, 2004.

GIL, A. C. Como elaborar projetos de pesquisa. 5. ed. São Paulo: Atlas, 2010.

INTERNATIONAL ACCOUNTING EDUCATION STANDARDS BOARD (IAESB). Framework for International Education Standards for Professional Accountants and Aspiring Professional Accountants. New York: IFAC, 2015. Disponível em: $<$ https://www.ifac.org/system/files/publications/files/IAESB-Framework-for_IES-forProfessional-Accountants-and-Aspiring-Professional-Accountants.pdf $>$. Acesso em: jan. 2016.

Initial Professional Development 2 - Technical Competence (Revised). New York: IFAC, 2014a. Disponível em: < http://www.ifac.org/publications-resources/ies-2initial-professional-development-technical-competence-revised>. Acesso em: jan. 2016.

Initial Professional Development 3 - Professional Skills (Revised). New York: IFAC, 2014b. Disponível em: <http://www.ifac.org/publications-resources/ies-3-initialprofessional-development-professional-skills-revised>. Acesso em: jan. 2016

Initial Professional Development 4 - Professional Values, Ethics, and Attitudes (Revised). New York: IFAC, 2014c. Disponível em: < http://www.ifac.org/publications-resources/ies-4-initial-professional-developmentprofessional-values-ethics-and-attit-0>. Acesso em: jan. 2016.

INTERNATIONAL FEDERATION OF ACCOUNTANTS (IFAC). Nexus 1: The Accountancy Profession, Behind the Numbers. Disponível em: $<$ https://www.ifac.org/publications-resources/nexus-1-accountancy-profession-behindnumbers $>$. Acesso em: nov. 2015.

LEAL, E. A.; SOARES, M. A.; SOUSA, E. G. Perspectivas dos Formandos do Curso de Ciências Contábeis e as Exigências do Mercado de Trabalho. Revista Contemporânea de Contabilidade, ISSN 1807-1821, UFSC, Florianópolis, ano 05, v.01, n.10, p. 147-159, jul./dez., 2008.

LEMES, D. F. Habilidades Profissionais do Contador Preconizadas pela Ifac: Um Estudo com Profissionais da Região do Triângulo Mineiro. In: CONGRESSO USP DE INICIAÇÃO CIENTÍfICA EM CONTABILIDADE, 10., 2013, São Paulo. Anais... São Paulo, 2013.

NUNES, I. V.; SILVA, T. D.; MIRANDA, G. J.; LEAL, E. A. Sou vestibulando, mas... O que faz um Contador? In: CONGRESSO UFSC DE INICIAÇÃO CIENTÍFICA EM CONTABILIDADE, 5. 2014. Florianópolis. Anais... Florianópolis, 2014.

OLIVEIRA, H. M. de, SILVA, J. O. da. Perfil Profissional Contábil: Um Estudo de Suas Habilidades. In: CONGRESSO UFSC DE CONTROLADORIA E FINANÇAS \& INICIAÇÃO CIENTÍFICA EM CONTABILIDADE, 5., 2014, Florianópolis. Anais... Florianópolis, 2014. 
BARRESE, P. F.; BASTONI, T. R.; NOGUEIRA, D. R. Percepção sobre o desenvolvimento de competências profissionais no curso de ciências contábeis de acordo com o IAESB: uma análise com os egressos de 2011 a 2015. Revista Unemat de Contabilidade, 2017. v. 6, n. 11.

OTT, E.; PIRES, C. B. Estrutura Curricular do Curso de Ciências Contábeis no Brasil versus Estruturas Curriculares Propostas por Organismos Internacionais: uma análise comparativa. Revista Universo Contábil, ISSN 1809-3337, FURB, Blumenau, v.6, n.1, p. 28-45, jan./mar., 2010.

PALLANT, J. SPSS Survival manual. 2. ed. Chicago: Open University, 2005.

REIS, A. de O.; MOREIRA, V. de S.; SEDIYAMA, G. A. S.; MOREIRA, C. C. Perfil Profissional Contábil: Habilidades, Competências e Imagem Simbólica. In: CONGRESSO USP DE CONTROLADORIA E CONTABILIDADE, 14, 2014, São Paulo. Anais... São Paulo, 2014. 